\title{
Research on the Fresh Agricultural Product Supply Chain Coordination with Supply Disruptions
}

\author{
Sun Guohua \\ School of Management Science and Engineering, Shandong University of Finance and Economics, Jinan 250014, China \\ Correspondence should be addressed to Sun Guohua; sungh@sdu.edu.cn
}

Received 16 December 2012; Accepted 8 February 2013

Academic Editor: Xiang Li

Copyright ( 2013 Sun Guohua. This is an open access article distributed under the Creative Commons Attribution License, which permits unrestricted use, distribution, and reproduction in any medium, provided the original work is properly cited.

\begin{abstract}
This paper develops a dynamic model in a one-supplier-one-retailer fresh agricultural product supply chain that experiences supply disruptions during the planning horizon. The optimal solutions in the centralized and decentralized supply chains are studied. It is found that the retailer's optimal order quantity and the maximum total supply chain profit in the decentralized supply chain with wholesale price contract are less than that in the centralized supply chain. A two-part tariff contract is proposed to coordinate the decentralized supply chain with which the maximum profit can be achieved. It is found that the optimal wholesale price should be a decreasing piecewise function of the final output. To ensure that the supplier and the retailer both have incentives to accept the coordination contract, a lump-sum fee is offered. The interval of lump-sum fee is given leaving both the supplier and the retailer better off with the two-part tariff contract.
\end{abstract}

\section{Introduction}

Agriculture plays a vital role in the world economy. However, the production of most agricultural products is affected by a lot of external factors, such as the weather changes, seeds quality, and culture methods, which are not in full control by the supply chain members. The situation is further complicated by the fact that there is a long lead time in the production of agricultural product. It means that it is impossible to adjust the production plan when the environment changes. For the agricultural product producers, they lack the market information and are not certain of the final output when going into production. They are more blindfold to choose what to produce and how much to produce, especially in the uncertain environment. Then oversupply and shortage of the agricultural product are quite popular in the agricultural product market, which reduce the profit of the supply chain and hurt the enthusiasms of the supply chain members. How to reduce the effects of the fluctuations and share the risks facing the supply chain members is an important topic in the supply chain management.

Coordinating supply chain has been a major issue in supply chain management research. Supply chain contracts are contractual agreements governing the pricing and exchange of goods or services between independent members in a supply chain. Properly designed supply contracts are an effective means to share the demand and supply risk and better coordinate the decentralized supply chain. It is widely recognized that the supplier and retailer can both benefit from coordination and thereby improve the overall performance of the supply chain as a whole. Many wellknown contract forms such as buy-back, revenue-sharing, quantity flexibility, sales rebate, two-part tariff, and quantity discount have shown to coordinate the supply chain. In this paper, a dynamic model in a one-supplier-one-retailer fresh agricultural product supply chain that experiences supply disruptions during the planning horizon is studied. The twopart tariff contract that can coordinate the fresh agricultural product supply chain with supply disruptions effectively is determined.

The remainder of the paper is organized as follows. In the next section, a brief literature review and a summary of the contributions of this research are provided. Section 3 introduces the notations and formulates the decision models. In Section 4, the centralized supply chain model is discussed. In Section 5, the fresh agricultural product supply chain in 
the decentralized case is studied. In Section 6, the design of coordination contract is given. The supply chain can be coordinated when the supplier and the retailer make decisions independently. A numerical example is given in Section 7. The work is summarized, and topics for future study are discussed in Section 8.

\section{Literature Review}

One stream of the literature related to the research is on fresh agricultural product supply chain. Samuel et al. [1] examined contract practices between suppliers and retailers in the agricultural seed industry. Xiao et al. [2] researched on the optimization and coordination of fresh-product supply chains under the Cost Insurance and Freight business model with uncertain long distance transportation delays and devised a simple cost sharing mechanism to coordinate the supply chain under consideration. Wang and Chen [3] introduced the options contracts into the fresh produce supply chain and took the huge circulation wastages both from quantity and quality into account. Cai et al. [4] considered a supply chain in which a fresh-product producer supplies the product to a distant market, via a specialized third-party logistics (3PL) provider, where a distributor purchases and sells it to end customers. An incentive scheme is proposed to coordinate the supply chain. Yu and Nagurney [5] developed a networkbased food supply chain model under oligopolistic competition and perishability with a focus on fresh produce and proposed an algorithm with elegant features for computation.

This paper is also closely related to supply chain coordination management and disruption management. In a decentralized decision-making setting, the optimal supply chain profit is usually not achieved due to double marginalization. Double marginalization means the fact that each supply chain member's relative cost structure is distorted when a transfer price is introduced within a supply chain. Designing coordination contract is an important issue which aimed at reconciling conflicts and achieves a better profit among supply chain members. Lariviere [6], Tsay et al. [7], and Cachon [8] provided excellent introduction and summaries on coordination contracts. Our coordination contract is closely related to Jeuland and Shugan [9], Moorthy [10], and Georges [11]. Georges [11] investigated under which conditions the manufacturer can reach the vertically integrated channel solution through the use of a two-part wholesale price in a static marketing channel where demand also depends on players' advertising.

For the literature on disruption management, Qi et al. [12] first introduced the disruption management into supply chain management. They investigate a one-supplier-oneretailer supply chain that experienced a disruption in demand during the planning horizon. They examined how the original production plan should be adjusted after demand disruptions occurred and how to coordinate the supply chain using wholesale quantity discount policies. Xiao et al. [13] further studied the coordination of the supply chain with demand disruptions and considered a price-subsidy rate contract to coordinate the investments of the competing retailers with sales promotion opportunities and demand disruptions. Xiao and $\mathrm{Yu}$ [14] developed an indirect evolutionary game model with two vertically integrated channels to study evolutionarily stable strategies (ESS) of retailers in the quantity-setting duopoly situation with homogeneous goods and analyzed the effects of the demand and raw material supply disruptions on the retailers' strategies. Xiao and Qi [15] studied the disruption management of the supply chain with two competing retailers, where the manufacturer faces a production cost disruption. Chen and Xiao [16] developed two coordination models of a supply chain consisting of one manufacturer, one dominant retailer, and multiple fringe retailers to investigate how to coordinate the supply chain after demand disruption. They considered two coordination schedules, linear quantity discount schedule and Groves wholesale price schedule. Li et al. [17] investigated the sourcing strategy of a retailer and the pricing strategies of two suppliers in a supply chain under an environment of supply disruption. They characterized the sourcing strategies of the retailer in a centralized and a decentralized system. They derived a sufficient condition for the existence of an equilibrium price in the decentralized system when the suppliers were competitive. Huang et al. [18] developed a two-period pricing and production decision model in a one-manufacturerone-retailer dual-channel supply chain that experienced a disruption in demand during the planning horizon. They studied the scenarios where the manufacturer and the retailer were in a vertically integrated setting and in a decentralized decision-making setting. They derived conditions under which the maximum profit can be achieved. Anastasios et al. [19] proposed generic single period inventory models for capturing the tradeoff between inventory policies and disruption risks in a dual-sourcing supply chain network both unconstrained and under service level constraints, where both supply channels were susceptible to disruption risks. The models were developed for both risk-neutral and risk-averse decision-makers and can be applicable for different types of disruptions.

There are two main differences between the works cited and the paper. First, most previous results are dependent on the assumption that the supply is deterministic or obeys a certain distribution. Only few studies examine the supply chain with supply disruptions. Second, most research related to the supply chain disruptions focuses on the demand disruptions. In this paper, a dynamic model in a one-supplierone-retailer fresh agricultural product supply chain that experiences supply disruptions during the planning horizon is proposed, and the agricultural product supply chain with supply disruptions is coordinated.

\section{Problem Description}

A fresh agricultural product supply chain composed of a supplier and a retailer is studied in the paper. The supplier produces fresh agricultural product with a long production lead time and a short lifecycle. The supplier sells the fresh agricultural product to the retailer, and the retailer sells the product to the customers in a single selling season. The supplier and the retailer are assumed to be risk neutral and pursue profit maximization. 
The demand of the fresh agricultural product is $d=$ $D-k p$, where $D$ is the market scale, $k$ is the price-sensitive coefficient, and $d$ is the real demand under the unit retail price $p$.

Since the supplier produces fresh agricultural product with a long production lead time, the supplier must make the production plan before the retailer makes the order decision. While making the production plan, the supplier does not consider the supply disruptions, since the supply disruptions cannot be anticipated. Usually there is no supply disruption, that is, the supplier puts $q_{s}$ units into production, and the final output is exactly $q_{s}$ units. If there are supply disruptions, the supplier still puts $q_{s}$ units into production and the final output is uncertain to be $q_{s}$.

When the agricultural product harvests and the selling season comes, the final output of the supplier is found to be $Q\left(=q_{s}+\Delta q_{s}\right)$, where the supply disruptions are captured by the term $\Delta q_{s}$. To be reasonable, there is an upper bound $\Delta \bar{q}_{s}$ of $\Delta q_{s}$ and a lower bound $\Delta \underline{q}_{s}$ of $\Delta q_{s}$, where $\Delta \bar{q}_{s} \geq 0$ and $\Delta q \leq 0$. The upper bound of final output is $\bar{Q}\left(=q_{s}+\Delta \bar{q}_{s}\right)$, and the lower bound of final output is $Q\left(=q_{s}+\Delta \underline{q}_{s}\right)$. After the final output is realized, the supplier decides the wholesale price, and the retailer makes the order decision according to the wholesale price. The paper focuses on the decision-making problem after the supply disruptions happen.

$c$ is the unit distributing cost of the fresh agricultural product from the supplier to the retailer. $p_{s}$ is the unit supplying cost from the spot market incurred by the supplier when the retailer's demand cannot be satisfied by the product produced by the supplier, and $v_{s}$ is unit salvage cost of the supplier when there are surplus products. To be reasonable, the following assumption is given.

Assumption $1\left(c>v_{s}\right) \cdot c>v_{s}$ is assumed, otherwise the supplier can earn infinite profit by distributing infinite products.

Assumption $2\left(p_{s}>v_{s}\right) . p_{s}>v_{s}$ is assumed since the fresh agricultural product is of little salvage value.

The following mathematical notation is used. $\pi_{j}^{i}$ denotes the profit function for channel member $j$ in supply chain model $i$. Superscript $i$ takes values $I D, D$, and $C$, which denote the centralized supply chain, decentralized supply chain and supply chain with coordination contract, respectively. The subscript $j$ takes values $r$ and $s$, which denotes the retailer and the supplier.

\section{The Centralized Supply Chain with Supply Disruptions}

It is obvious that the supply chain performs best if the channel is centrally controlled. The decision variable in the centralized supply chain is only the order quantity $q$.

When the supplier's final output is $Q$, the total supply chain profit is

$$
\pi^{I D}(q)=q\left(\frac{D-q}{k}-c\right)+v_{s}(Q-q)^{+}-p_{s}(q-Q)^{+}
$$

The following conclusions about the optimal order quantity in the centralized agricultural product supply chain are got.

Theorem 1. When the final output is $Q$, the optimal order quantity $q^{I D^{*}}$ of the retailer is

(i) when $\underline{Q} \leq Q \leq\left(D-k\left(c+p_{s}\right)\right) / 2, q^{I D^{*}}=(D-k(c+$ $\left.\left.p_{s}\right)\right) / 2$;

(ii) when $\left(D-k\left(c+p_{s}\right)\right) / 2 \leq Q \leq\left(D-k\left(c+v_{s}\right)\right) / 2$, $q^{I D^{*}}=Q$

(iii) when $\left(D-k\left(c+v_{s}\right)\right) / 2 \leq Q \leq \bar{Q}, q^{I D^{*}}=(D-k(c+$ $\left.\left.v_{s}\right)\right) / 2$.

From Theorem 1, the optimal profit in the centralized agricultural product supply chain can be got.

Theorem 2. When the final output is $\mathrm{Q}$, the maximum total profit in the centralized supply chain $\pi^{I D^{*}}$ is

(i) when $\underline{Q} \leq Q \leq\left(D-k\left(c+p_{s}\right)\right) / 2, \pi^{I D^{*}}=(1 / k)[(D-$ $\left.\left.k\left(c+\bar{p}_{s}\right)\right) / 2\right]^{2}+p_{s} Q$

(ii) when $\left(D-k\left(c+p_{s}\right)\right) / 2 \leq Q \leq\left(D-k\left(c+v_{s}\right)\right) / 2$, $\pi^{I D^{*}}=Q(((D-Q) / k)-c) ;$

(iii) when $\left(D-k\left(c+v_{s}\right)\right) / 2 \leq Q \leq \bar{Q}, \pi^{I D^{*}}=(1 / k)[(D-$ $\left.\left.k\left(c+v_{s}\right)\right) / 2\right]^{2}+v_{s} Q$.

\section{The Decentralized Supply Chain with Supply Disruptions}

In this section, the problem that the supplier and the retailer make decisions with wholesale price contract in a decentralized way under the disrupted output is discussed. In this case, the supplier acts as the leader, and the retailer acts as the follower. When the agricultural product harvests, the supplier first decides on the wholesale price $\omega$, and the retailer decides the order quantity $q$ accordingly. The supplier distributes $q$ units fresh agricultural product to the retailer. If the final output cannot satisfy the retailer, the supplier buys the remaining products from the spot market. If there is surplus after satisfying the retailer, the residual products are salvaged.

Because the supplier is the leader, the best-response function of the retailer should be got at first. For a given $\omega$, the retailer's profit is

$$
\pi_{r}^{D}(q)=q\left(\frac{D-q}{k}-\omega\right) .
$$

The retailer aims to maximize his profit. The objective function is concave in $\omega$, and the retailer's first-order conditions characterize the unique best response: $q_{r}^{D^{*}}(\omega)=(D-$ $k \omega) / 2$.

The supplier's optimization problem can be stated as

$$
\pi_{s}^{D}(q)=(\omega-c) q_{r}^{D^{*}}+v_{s}\left(Q-q_{r}^{D^{*}}\right)^{+}-p_{s}\left(q_{r}^{D^{*}}-Q\right)^{+} .
$$


Lemma 3. When the final output is $Q$, the optimal wholesale price $\omega^{D^{*}}$ of the supplier is

(i) when $Q \leq Q \leq\left(D-k\left(c+p_{s}\right)\right) / 4, \omega^{D^{*}}=(D+k(c+$ $\left.\left.p_{s}\right)\right) / 2 \bar{k}$;

(ii) when $\left(D-k\left(c+p_{s}\right)\right) / 4 \leq Q \leq\left(D-k\left(c+v_{s}\right)\right) / 4$, $\omega^{D^{*}}=(D-2 Q) / k$;

(iii) when $\left(D-k\left(c+v_{s}\right)\right) / 4 \leq Q \leq \bar{Q}, \omega^{D^{*}}=(D+k(c+$ $\left.\left.v_{s}\right)\right) / 2 k$.

It is not hard to get Theorems 4 and 5 from Lemma 3.

Theorem 4. When the final output is $Q$, the optimal order quantity $q_{r}^{D^{*}}$ of the retailer is

(i) when $Q \leq Q \leq\left(D-k\left(c+p_{s}\right)\right) / 4, q_{r}^{D^{*}}=\left(D-k\left(p_{s}+\right.\right.$ c)) $/ 4$;

(ii) when $\left(D-k\left(c+p_{s}\right)\right) / 4 \leq Q \leq\left(D-k\left(c+v_{s}\right)\right) / 4$, $q_{r}^{D^{*}}=Q$

(iii) when $\left(D-k\left(c+v_{s}\right)\right) / 4 \leq \mathrm{Q} \leq \overline{\mathrm{Q}}, q_{r}^{D^{*}}=\left(D-k\left(v_{s}+\right.\right.$ c)) $/ 4$.

Theorem 5. When the final output is $Q$, the maximum supplier profit $\pi_{s}^{D^{*}}$, the maximum retailer profit $\pi_{r}^{D^{*}}$, and the maximum total profit $\pi^{D^{*}}$ in the decentralized supply chain are

(i) when $Q \leq Q \leq\left(D-k\left(c+p_{s}\right)\right) / 4, \pi_{s}^{D^{*}}=(2 / k)[(D-$ $\left.\left.k\left(p_{s}+c\right)\right) / 4\right]^{2}+p_{s} Q, \pi_{r}^{D^{*}}=(1 / k)\left[\left(D-k\left(p_{s}+c\right)\right) / 4\right]^{2}$, $\pi^{D^{*}}=(3 / k)\left[\left(D-k\left(p_{s}+c\right)\right) / 4\right]^{2}+p_{s} Q ;$

(ii) when $\left(D-k\left(c+p_{s}\right)\right) / 4 \leq Q \leq\left(D-k\left(c+v_{s}\right)\right) / 4, \pi_{s}^{D^{*}}=$ $(((D-2 Q) / k)-c) Q, \pi_{r}^{D^{*}}=(1 / k) Q^{2}, \pi^{D^{*}}=(((D-$ $Q) / k)-c) Q$;

(iii) when $\left(D-k\left(c+v_{s}\right)\right) / 4 \leq Q \leq \bar{Q}, \pi_{s}^{D^{*}}=(2 / k)[(D-$ $\left.\left.k\left(v_{s}+c\right)\right) / 4\right]^{2}+v_{s} Q, \pi_{r}^{D^{*}}=(1 / k)\left[\left(D-k\left(v_{s}+c\right)\right) / 4\right]^{2}$, $\pi^{D^{*}}=(3 / k)\left[\left(D-k\left(v_{s}+c\right)\right) / 4\right]^{2}+v_{s} Q$.

Theorem 6. The optimal order quantity in the centralized and decentralized supply chains with supply disruptions satisfies $q_{r}^{D^{*}} \leq q^{I D^{*}}$.

Let $q_{1}^{D^{*}}=\left(D-k\left(c+v_{s}\right)\right) / 4, q_{2}^{D^{*}}=\left(D-k\left(c+p_{s}\right)\right) / 4$, $q_{1}^{I D^{*}}=\left(D-k\left(c+v_{s}\right)\right) / 2$, and $q_{2}^{I D^{*}}=\left(D-k\left(c+p_{s}\right)\right) / 2$; the relation between the optimal order quantity and the final output is shown in Figure 1. The optimal order quantity in the decentralized supply chain is always less than that in the centralized supply chain.

From Theorems 2 and 5, Theorem 7 can be got.

Theorem 7. The maximum total supply chain profits in the centralized and decentralized supply chains with supply disruptions satisfy $\pi^{I D^{*}} \geq \pi^{D^{*}}$.

From Theorem 7, the maximum total supply chain profit in the decentralized supply chain is less than that in the centralized supply chain. In the next section, it is shown that the

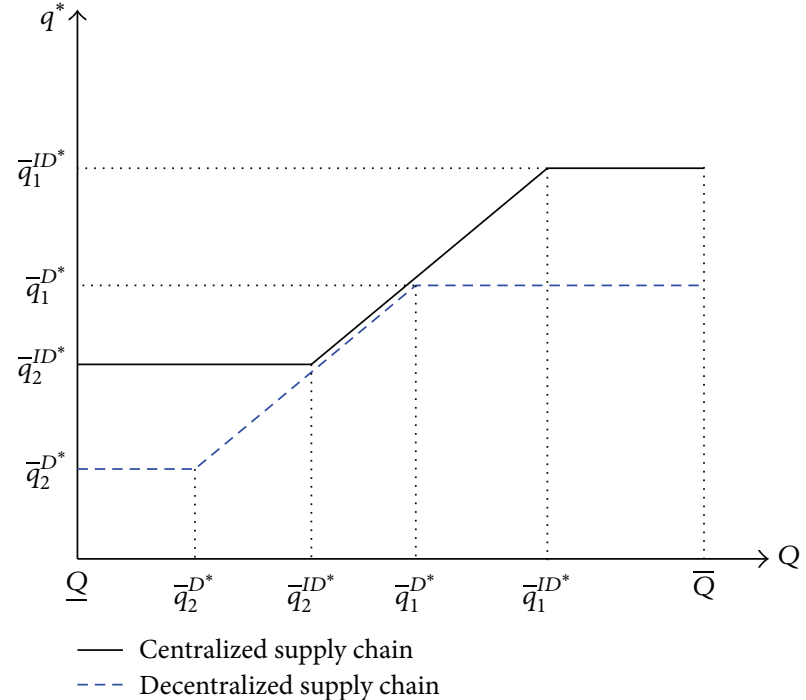

(a) $\bar{q}_{2}^{I D^{*}} \leq \bar{q}_{1}^{D^{*}}$

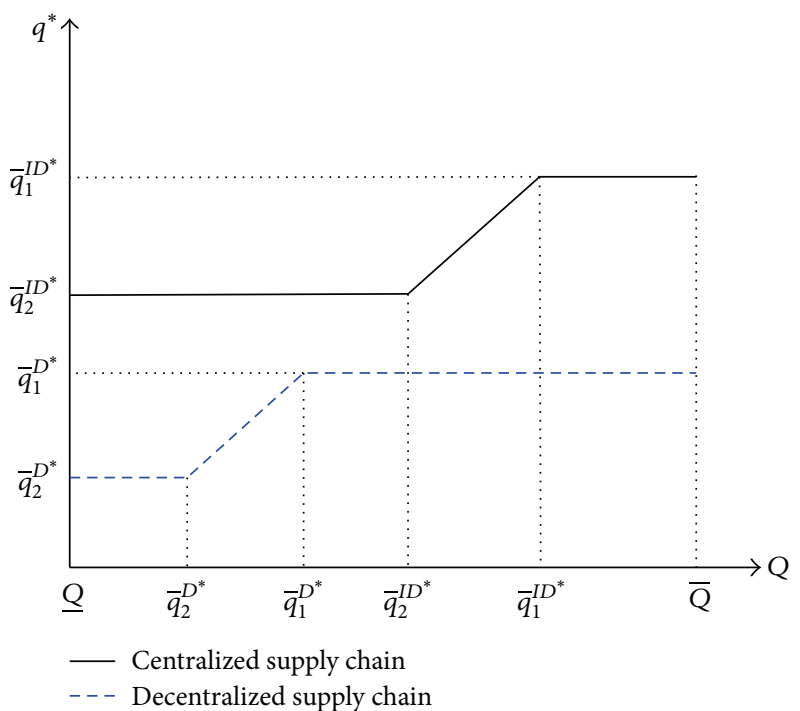

(b) $\bar{q}_{1}^{D^{*}} \leq \bar{q}_{2}^{I D^{*}}$

FIGURE 1: Relation between optimal order quantity and final output.

supplier can further improve the profits in the decentralized supply chain by offering the coordination contract.

\section{Design of Coordination Contract}

In Section 5, it is shown that when the supplier and the retailer make decisions in a decentralized way, the wholesale price contract cannot coordinate the supply chain and must be modified to achieve the optimal total supply chain profit.

Theorem 8. When the final output is $Q$, to ensure that the retailer's order quantity equals the optimal order quantity in the centralized supply chain, the optimal wholesale price $\omega^{\mathrm{C}^{*}}$ is

(i) when $Q \leq Q \leq\left(D-k\left(c+p_{s}\right)\right) / 2, \omega^{C^{*}}=c+p_{s}$; 
(ii) when $\left(D-k\left(c+p_{s}\right)\right) / 2 \leq Q \leq\left(D-k\left(c+v_{s}\right)\right) / 2$, $\omega^{C^{*}}=(D-2 Q) / k$;

(iii) when $\left(D-k\left(c+v_{s}\right)\right) / 2 \leq Q \leq \bar{Q}, \omega^{C^{*}}=c+v_{s}$.

From Theorem 8, Theorem 9 can be obtained.

Theorem 9. When the wholesale price $\omega^{*}=\omega^{C^{*}}$, the decentralized supply chain can be coordinated.

When the wholesale price $\omega^{*}=\omega^{C^{*}}$, the profits of the supplier and the retailer are

(i) when $Q \leq Q \leq\left(D-k\left(c+p_{s}\right)\right) / 2, \pi_{s}^{C^{*}}=p_{s} Q, \pi_{r}^{C^{*}}=$ $(1 / k)\left[\left(D-k\left(p_{s}+c\right)\right) / 2\right]^{2}$;

(ii) when $\left(D-k\left(c+p_{s}\right)\right) / 2 \leq Q \leq\left(D-k\left(c+v_{s}\right)\right) / 2$, $\pi_{s}^{C^{*}}=(((D-2 Q) / k)-c) Q, \pi_{r}^{C^{*}}=Q^{2} / k$;

(iii) when $\left(D-k\left(c+v_{s}\right)\right) / 2 \leq Q \leq \bar{Q}, \pi_{s}^{C^{*}}=v_{s} Q, \pi_{r}^{C^{*}}=$ $(1 / k)\left[\left(D-k\left(c+v_{s}\right)\right) / 2\right]^{2}$.

It can be verified that $\pi_{s}^{C^{*}}+\pi_{r}^{C^{*}}=\pi^{I D^{*}}$.

Theorem 8 indicates that, in a decentralized supply chain, to coordinate the fresh agricultural product supply chain with supply disruptions, the optimal wholesale price depends on the final output. The optimal wholesale price is a decreasing piecewise function of final output. To ensure that the supplier and the retailer both have incentives to accept the coordination contract, the profits of the supplier and the retailer should satisfy $\pi_{s}^{C} \geq \pi_{s}^{D^{*}}, \pi_{r}^{C} \geq \pi_{r}^{D^{*}}$. This problem can be easily solved by offering a lump-sum fee $F(\underline{F} \leq F \leq \bar{F})$, where $\underline{F}=\max \left(\pi_{s}^{D^{*}}-\pi_{s}^{C^{*}}, \pi_{r}^{D^{*}}-\pi_{r}^{C^{*}}, 0\right), \bar{F}=\max \left(\pi_{s}^{C^{*}}-\right.$ $\pi_{s}^{D^{*}}, \pi_{r}^{C^{*}}-\pi_{r}^{D^{*}}$ ). (Since $\pi_{s}^{C^{*}}+\pi_{r}^{C^{*}} \geq \pi_{s}^{D^{*}}+\pi_{r}^{D^{*}}, \underline{F}$ and $\bar{F}$ are different.) When $\pi_{s}^{D^{*}} \geq \pi_{s}^{C^{*}}$, that is, the supplier earns less with the coordination contract, the retailer should pay the lump-sum fee $F$ to the supplier. The profits of the supplier and the retailer are $\pi_{s}^{C}=\pi_{s}^{C^{*}}+F, \pi_{r}^{C}=\pi_{r}^{C^{*}}-F$. Otherwise, the supplier should pay the lump-sum fee $F$ to the retailer. The profits of the supplier and the retailer are $\pi_{s}^{C}=\pi_{s}^{C^{*}}-F$, $\pi_{r}^{C}=\pi_{r}^{C^{*}}+F$. Then $\pi_{s}^{C} \geq \pi_{s}^{D^{*}}$ and $\pi_{r}^{C} \geq \pi_{r}^{D^{*}}$ are satisfied.

\section{Numerical Example}

A numerical example is given to illustrate some of results derived throughout the paper.

Suppose the supplier's unit distribution $\operatorname{cost} c=2$, the unit buying cost $p_{s}=5$, and the unit salvage cost $v_{s}=1$. The demand function is $q=40-p$.

When there are supply disruptions and the supplier's production is $q_{s}$, the final output $Q$ is not certain. The supply disruptions are captured by the term $\Delta q_{s}$, where $\Delta q_{s}$ lies in the interval $\left[-q_{s}, 0.5 q_{s}\right]$. That is, the final output $Q$ lies in the interval $[\mathrm{Q}, \overline{\mathrm{Q}}]$, where $\mathrm{Q}=0, \overline{\mathrm{Q}}=1.5 q_{s}$.

When the supply disruptions happen and the final output is found to be $Q$, in the centralized supply chain, the retailer's optimal order quantity $q^{I D^{*}}$ is (i) when $0 \leq Q \leq 16.5$,
$q^{I D^{*}}=16.5$; (ii) when $16.5 \leq Q \leq 18.5, q^{I D^{*}}=Q$; (iii) when $18.5 \leq Q \leq \bar{Q}, q^{I D^{*}}=18.5$.

Correspondingly, the maximum supply chain profit $\pi^{I D^{*}}$ is

(i) when $0 \leq Q \leq 16.5, \pi^{I D^{*}}=272.25+5 Q$;

(ii) when $16.5 \leq Q \leq 18.5, \pi^{I D^{*}}=Q(38-Q)$;

(iii) when $18.5 \leq Q \leq \bar{Q}, \pi^{I D^{*}}=342.25+Q$.

In the decentralized agricultural product supply chain, when the supply disruptions happen and the final output is found to be $Q$, the optimal wholesale price $\omega^{D^{*}}$ of the supplier is (i) when $0 \leq Q \leq 8.25, \omega^{D^{*}}=23.5$; (ii) when $8.25 \leq Q \leq$ 9.25, $\omega^{D^{*}}=40-2 Q$; (iii) when $9.25 \leq Q \leq \bar{Q}, \omega^{D^{*}}=21.5$.

Correspondingly, the optimal order quantity $q_{r}^{D^{*}}$ of the retailer is (i) when $0 \leq Q \leq 8.25, q_{r}^{D^{*}}=8.25$; (ii) when $8.25 \leq$ $Q \leq 9.25, q_{r}^{D^{*}}=Q$; (iii) when 9.25 $\leq Q \leq \bar{Q}, q_{r}^{D^{*}}=9.25$.

The supplier profit $\pi_{s}^{D^{*}}$, the retailer profit $\pi_{r}^{D^{*}}$, and total supply chain profit $\pi^{D^{*}}$ are

(i) when $0 \leq Q \leq 8.25, \pi_{s}^{D^{*}}=136.125+5 Q, \pi_{r}^{D^{*}}=$ $68.0625, \pi^{D^{*}}=204.1875+5 Q$

(ii) when $8.25 \leq Q \leq 9.25, \pi_{s}^{D^{*}}=(38-2 Q) Q, \pi_{r}^{D^{*}}=Q^{2}$, $\pi^{D^{*}}=(38-Q) Q$

(iii) when $9.25 \leq \mathrm{Q} \leq \overline{\mathrm{Q}}, \pi_{s}^{D^{*}}=171.125+\mathrm{Q}, \pi_{r}^{D^{*}}=$ $85.5625, \pi^{D^{*}}=256.6875+Q$.

For a given final output $Q$, it can be verified that $q_{r}^{D^{*}} \leq$ $q^{I D^{*}}, \pi^{D^{*}} \leq \pi^{I D^{*}}$. The decentralized supply chain should be coordinated to achieve the optimal total supply chain profit. To ensure that the retailer's order quantity in the decentralized supply chain equals that in the centralized supply chain, the optimal wholesale price $\omega^{C^{*}}$ is (i) when $0 \leq Q \leq 16.5, \omega^{C^{*}}=7$; (ii) when $16.5 \leq Q \leq 18.5, \omega^{C^{*}}=40-$ $2 Q$; (iii) when $18.5 \leq Q \leq \bar{Q}, \omega^{C^{*}}=3$.

The retailer's profit is (i) when $0 \leq Q \leq 16.5, \pi_{r}^{C}(q)=$ $q(33-q)$; (ii) when $16.5 \leq Q \leq 18.5, \pi_{r}^{C}(q)=2 q Q$; (iii) when $18.5 \leq Q \leq \bar{Q}, \pi_{r}^{C}(q)=q(37-q)$.

Then the retailer's optimal order quantity is (i) when $0 \leq$ $\mathrm{Q} \leq 16.5, q_{r}^{C^{*}}=16.5$; (ii) when $16.5 \leq \mathrm{Q} \leq 18.5, q_{r}^{C^{*}}=Q$; (iii) when $18.5 \leq Q \leq \bar{Q}, q_{r}^{C^{*}}=18.5$.

Correspondingly, the maximum supplier profit $\pi_{s}^{D^{*}}$, the maximum retailer profit $\pi_{r}^{D^{*}}$, and the maximum total profit $\pi^{D^{*}}$ in the decentralized supply chain are

(i) when $0 \leq Q \leq 16.5, \pi_{s}^{C^{*}}=5 Q, \pi_{r}^{C^{*}}=272.25, \pi^{C^{*}}=$ $272.25+5 Q$

(ii) when $16.5 \leq Q \leq 18.5, \pi_{s}^{C^{*}}=Q(38-2 Q), \pi_{r}^{C^{*}}=Q^{2}$, $\pi^{C^{*}}=Q(38-Q)$;

(iii) when $18.5 \leq Q \leq \bar{Q}, \pi_{s}^{C^{*}}=Q, \pi_{r}^{C^{*}}=342.25, \pi^{C^{*}}=$ $342.25+Q$. 
It is obvious that $\pi^{C^{*}}=\pi^{I D^{*}}$, and the supply chain is coordinated.

To ensure that the supplier and the retailer both have incentives to accept the coordination contract, the profits of the supplier and the retailer should satisfy $\pi_{s}^{C} \geq \pi_{s}^{D^{*}}, \pi_{r}^{C} \geq$ $\pi_{r}^{D^{*}}$.

(i) When $0 \leq \mathrm{Q} \leq 8.25, \pi_{s}^{D^{*}} \geq \pi_{s}^{C^{*}}, \pi_{r}^{D^{*}} \leq \pi_{r}^{C^{*}}$. In this case, $\underline{F}=\pi_{s}^{D^{*}}-\pi_{s}^{C^{*}}=136.125, \bar{F}=\pi_{r}^{C^{*}}-\pi_{r}^{D^{*}}=$ 204.1875 , and the retailer should pay the supplier a lump-sum fee $F(\underline{F} \leq F \leq \bar{F})$. The profits of the supplier and the retailer are $\pi_{s}^{C}=\pi_{s}^{C^{*}}+F, \pi_{r}^{C}=$ $\pi_{r}^{C^{*}}-F$.

(ii) When $8.25 \leq \mathrm{Q} \leq 9.25, \pi_{s}^{D^{*}} \geq \pi_{s}^{C^{*}}, \pi_{r}^{D^{*}} \leq \pi_{r}^{C^{*}}$. In this case, $\underline{F}=\pi_{s}^{D^{*}}-\pi_{s}^{C^{*}}=Q(33-2 Q), \bar{F}=\pi_{r}^{C^{*}}-$ $\pi_{r}^{D^{*}}=272.25-Q^{2}$, and the retailer should pay the supplier a lump-sum fee $F(\underline{F} \leq F \leq \bar{F})$. The profits of the supplier and the retailer are $\pi_{s}^{C}=\pi_{s}^{C^{*}}+F, \pi_{r}^{C}=$ $\pi_{r}^{C^{*}}-F$.

(iii) When $9.25 \leq \mathrm{Q} \leq 16.5, \pi_{s}^{D^{*}} \geq \pi_{s}^{C^{*}}, \pi_{r}^{D^{*}} \leq \pi_{r}^{C^{*}}$. In this case, $\underline{F}=\pi_{s}^{D^{*}}-\pi_{s}^{C^{*}}=171.125-4 Q, \bar{F}=$ $\pi_{r}^{C^{*}}-\pi_{r}^{D^{*}}=186.6875$, and the retailer should pay the supplier a lump-sum fee $F(\underline{F} \leq F \leq \bar{F})$. The profits of the supplier and the retailer are $\pi_{s}^{C}=\pi_{s}^{C^{*}}+F, \pi_{r}^{C}=$ $\pi_{r}^{C^{*}}-F$.

(iv) When $16.5 \leq Q \leq 18.5, \pi_{s}^{D^{*}} \geq \pi_{s}^{C^{*}}, \pi_{r}^{D^{*}} \leq \pi_{r}^{C^{*}}$. In this case, $\underline{F}=\pi_{s}^{D^{*}}-\pi_{s}^{C^{*}}=171.125-37 Q+2 Q^{2}, \bar{F}=$ $\pi_{r}^{C^{*}}-\pi_{r}^{D^{*}}=38 Q-Q^{2}-85.5625$. The retailer should pay the supplier a lump-sum fee $F(\underline{F} \leq F \leq \bar{F})$. The profits of the supplier and the retailer are $\pi_{s}^{C}=\pi_{s}^{C^{*}}+F$, $\pi_{r}^{C}=\pi_{r}^{C^{*}}-F$.

(v) When $18.5 \leq Q \leq \bar{Q}, \pi_{s}^{D^{*}} \geq \pi_{s}^{C^{*}}, \pi_{r}^{D^{*}} \leq \pi_{r}^{C^{*}}$. In this case, $\underline{F}=\pi_{s}^{D^{*}}-\pi_{s}^{C^{*}}=171.125, \bar{F}=\pi_{r}^{C^{*}}-\pi_{r}^{D^{*}}=$ 256.6875 , and the retailer should pay the supplier a lump-sum fee $F(\underline{F} \leq F \leq \bar{F})$. The profits of the supplier and the retailer are $\pi_{s}^{C}=\pi_{s}^{C^{*}}+F, \pi_{r}^{C}=$ $\pi_{r}^{C^{*}}-F$. Then $\pi_{s}^{C} \geq \pi_{s}^{D^{*}}$ and $\pi_{r}^{C} \geq \pi_{r}^{D^{*}}$ is satisfied.

The supplier and the retailer both benefit from the coordination contract and have incentives to accept the contract.

\section{Summary and Conclusions}

In this paper, supply disruptions are introduced in the analysis of a one-supplier-one-retailer fresh agricultural product supply chain. The optimal decisions in the centralized and decentralized supply chain are analyzed. It is found that the retailer's optimal order quantity and the maximum total supply chain profit in the decentralized supply chain are less than that in the centralized supply chain. A two-part tariff contract is proposed. It shows that the supply chain can be coordinated leaving both the supplier and the retailer better off with a two-part tariff contract.

The aim of the paper is to develop a supply chain coordination scheme for adjusting the sale plan after supply disruptions occur, rather than making decisions considering all possible uncertainties in the planning stage. Of course, formulating a good plan based on certain probability assumptions is important, but, realistically, it is not possible for the decision-maker to anticipate all contingencies. In practice, for most agricultural products, the final output cannot be estimated precisely, so providing guidance for adjusting a predetermined plan can be as important as making the plan itself.

In the paper, one-supplier-one-retailer fresh agricultural product supply chain is studied. There are abundant opportunities for research on extensions ranging from multiple suppliers, multiple periods, and longer supply chains.

\section{Appendix}

Proof of Theorem 1. (i) When $q \leq Q$, the supply chain profit is $\pi_{1}^{I D}(q)=q(((D-q) / k)-c)+v_{s}(Q-q)$, where $\pi_{1}^{I D}(q)$ is concave in $q$. The optimal solution without constraint is $\bar{q}_{1}^{I D^{*}}=(D-$ $\left.k\left(c+v_{s}\right)\right) / 2$. Then if $\bar{q}_{1}^{*} \leq Q$, the optimal order quantity is $q_{1}^{I D^{*}}=\bar{q}_{1}^{I D^{*}}$, and the maximum supply chain profit is $\pi_{1}^{I D^{*}}=$ $(1 / k) \bar{q}_{1}^{I D^{*} 2}+v_{s} Q$. Otherwise, the optimal solution is $q_{1}^{I D^{*}}=Q$. Correspondingly, the maximum supply chain profit is $\pi_{1}^{I D^{*}}=$ $Q(((D-Q) / k)-c)$.

(ii) When $q \geq Q$, the supply chain profit is: $\pi_{2}^{I D}(q)=$ $q(((D-q) / k)-c)-p_{s}(q-Q)$, where $\pi_{2}^{I D}(q)$ is concave in $q$. The optimal solution without constraint is $\bar{q}_{2}^{I D^{*}}=(D-$ $\left.k\left(c+p_{s}\right)\right) / 2$. Then if $\bar{q}_{2}^{I D^{*}} \geq \mathrm{Q}$, the optimal order quantity is $q_{2}^{I D^{*}}=\bar{q}_{2}^{I D^{*}}$, and the maximum supply chain profit is $\pi_{2}^{I D^{*}}=(1 / k) \bar{q}_{2}^{I D^{*} 2}-p_{s} Q$. Otherwise, the optimal solution is: $q_{2}^{I D^{*}}=Q$. Correspondingly, the maximum supply chain profit is $\pi_{2}^{I D^{*}}=Q(((D-Q) / k)-c)$.

With Assumption 1, it is not hard to verify $\bar{q}_{1}^{I D^{*}} \geq \bar{q}_{2}^{I D^{*}}$.

(i) When $Q \leq \bar{q}_{2}^{I D^{*}}$, if the retailer chooses to order more than $Q$ unit products, the maximum supply chain profit is $\pi^{I D^{*}}=(1 / k) \bar{q}_{2}^{I D^{*} 2}-p_{s} Q$; otherwise, if the retailer orders $Q$ unit products from the supplier, the maximum supply chain profit is $\pi^{I D^{*}}=Q(((D-Q) / k)$ $-c)$. As $\pi_{2}^{I D}(Q)=\pi_{1}^{I D}(Q)$ and $\pi_{2}^{I D}\left(\bar{q}_{2}^{I D^{*}}\right) \geq \pi_{2}^{I D}(Q)$, the optimal order quantity is $q^{I D^{*}}=\left(D-k\left(c+p_{s}\right)\right) / 2$.

(ii) When $\bar{q}_{2}^{I D^{*}} \leq \mathrm{Q} \leq \bar{q}_{1}^{I D^{*}}$, if the retailer chooses to order less than $Q$ unit products, the supplier salvages some products. Since $\pi_{1}^{I D}(q)$ is increasing in $q$, the more the retailer orders, the more supply chain profit is got. Otherwise, if the retailer chooses to order more than $Q$ unit products, the supplier buys some products from the spot market. Since $\pi_{2}^{I D}(q)$ is decreasing in $q$, the more the retailer orders, the less supply chain profit is got. Then the optimal order quantity is $Q$. 
(iii) When $Q \geq \bar{q}_{1}^{I D^{*}}$, if the retailer chooses to order less than $Q$ unit products, the maximum supply chain profit is $\pi^{I D^{*}}=(1 / k) \bar{q}_{1}^{I D^{*} 2}+v_{s} Q$; otherwise if the retailer orders $Q$ unit products from the supplier, the maximum supply chain profit is $\pi^{I D^{*}}=Q(((D-Q) /$ $k)-c)$. As $\pi_{2}^{I D}(Q)=\pi_{1}^{I D}(Q)$ and $\pi_{1}^{I D}\left(\bar{q}_{1}^{I D^{*}}\right) \geq \pi_{1}^{I D}(Q)$, the optimal order quantity is $q^{I D^{*}}=\left(D-k\left(c+v_{s}\right)\right) / 2$.

Proof of Theorem 2. The total supply chain profit is $\pi^{I D}(q)=$ $q(((D-q) / k)-c)+v_{s}(Q-q)^{+}-p_{s}(q-Q)^{+}$. From Theorem 1 , the optimal profit of the centralized supply chain can be got.

Proof of Lemma 1. (i) When $Q \geq q$, the supply chain profit is $\pi_{s 1}^{D}(q)=(\omega-c) q+v_{s}(Q-q)$, where $\pi_{s 1}^{D}(q)$ is concave in $q$. The optimal solution without constraint is $\omega_{1}^{D^{*}}=(D+$ $\left.k\left(c+v_{s}\right)\right) / 2 k$. The retailer's order quantity is: $\bar{q}_{1}^{D^{*}}=(D-$ $\left.k\left(c+v_{s}\right)\right) / 4$. Then if $Q \geq\left(D-k\left(c+v_{s}\right)\right) / 4$, the optimal wholesale price is $\omega_{1}^{D^{*}}=\left(D+k\left(c+v_{s}\right)\right) / 2 k$. The supplier's profit is $\pi_{s 1}^{D^{*}}=(2 / k)\left[\left(D-k\left(c+v_{s}\right)\right) / 4\right]^{2}+v_{s} Q$. Otherwise, the optimal solution is $\omega_{1}^{D^{*}}=(D-2 Q) / k$. In this case, the retailer's order quantity is $q_{1}^{D^{*}}=Q$. Correspondingly, the maximum supply chain profit is: $\pi_{s 1}^{D^{*}}=Q(((D-2 Q) / k)-c)$.

(ii) When $Q \leq q$, the supply chain profit is $\pi_{s 2}^{D}(q)=$ $(\omega-c) q-p_{s}(q-Q)$, where $\pi_{s 2}^{D}(q)$ is concave in $q$. The optimal solution without constraint is $\omega_{2}^{D^{*}}=\left(D+k\left(c+p_{s}\right)\right) / 2 k$. The retailer's order quantity is: $\bar{q}_{2}^{D^{*}}=\left(D-k\left(c+p_{s}\right)\right) / 4$. Then if $Q \geq\left(D-k\left(c+p_{s}\right)\right) / 4$, the optimal wholesale price is $\omega_{2}^{D^{*}}=\left(D+k\left(c+p_{s}\right)\right) / 2 k$. The supplier's profit is $\pi_{s 1}^{D^{*}}=(2 / k)\left[\left(D-k\left(c+p_{s}\right)\right) / 4\right]^{2}+p_{s} Q$. Otherwise, the optimal solution is $\omega_{2}^{D^{*}}=(D-2 Q) / k$. In this case, the retailer's order quantity is $q_{2}^{D^{*}}=Q$. Correspondingly, the maximum supply chain profit is $\pi_{s 2}^{D^{*}}=Q(((D-2 Q) / k)-c)$.

With Assumption 1, it is not hard to verify $\bar{q}_{1}^{D^{*}} \geq \bar{q}_{2}^{D^{*}}$.

(i) When $Q \leq \bar{q}_{2}^{*}$, if the retailer chooses to order more than $Q$ unit products, the maximum supply chain profit is $\pi^{D^{*}}=(1 / k) \bar{q}_{2}^{D^{*} 2}-p_{s} Q$; otherwise if the retailer orders $Q$ unit products from the supplier, the maximum supply chain profit is $\pi^{D^{*}}=Q(((D-$ $Q) / k)-c)$. As $\pi_{2}^{D}(Q)=\pi_{1}^{D}(Q)$ and $\pi_{2}^{D}\left(\bar{q}_{2}^{D^{*}}\right) \geq \pi_{2}^{D}(Q)$; the optimal wholesale price is $\omega^{D^{*}}=(D+k(c+$ $\left.\left.p_{s}\right)\right) / 2 k$.

(ii) When $\bar{q}_{2}^{D^{*}} \leq Q \leq \bar{q}_{1}^{D^{*}}$, if the retailer chooses to order less than $Q$ unit products, the supplier salvages some products. Since $\pi_{1}^{D}(q)$ is increasing in $q$, the more the retailer orders, the more supply chain profit is got. Otherwise, if the retailer chooses to order more than $Q$ unit products, the supplier buys some products from the spot market. Since $\pi_{2}^{D}(q)$ is decreasing in $q$, the more the retailer orders, the less supply chain profit is got. Then the optimal order quantity is $Q$.

(iii) When $Q \geq \bar{q}_{1}^{D^{*}}$, if the retailer chooses to order less than $Q$ unit products, the maximum supply chain profit is $\pi^{D^{*}}=(1 / k) \bar{q}_{1}^{* 2}+v_{s} Q$; otherwise, if the retailer orders $Q$ unit products from the supplier, the maximum supply chain profit is $\pi^{D^{*}}=Q(((D-Q) / k)$ $-c)$. As $\pi_{2}^{D}(Q)=\pi_{1}^{D}(Q)$ and $\pi_{1}^{D}\left(\bar{q}_{1}^{D^{*}}\right) \geq \pi_{1}^{D}(Q)$, the optimal wholesale price is: $\omega^{D^{*}}=\left(D+k\left(c+v_{s}\right)\right) / 2 k$.

Proof of Theorem 3. From the retailer's best response $q_{r}^{D^{*}}(\omega)=(D-k \omega) / 2$ and the optimal wholesale price $\omega^{D^{*}}$ given in Lemma 3, the results in Theorem 4 are obtained.

Proof of Theorem 4. By substituting the optimal wholesale price $\omega^{D^{*}}$ given in Lemma 3 and the optimal order quantity given in Theorem 4 in $\pi_{r}^{D}(q), \pi_{s}^{D}(q)$, and $\pi_{r}^{D}(q)+\pi_{s}^{D}(q)$, the results in Theorem 5 are obtained.

Proof of Theorem 5. It is not hard to verify $\bar{q}_{1}^{D^{*}} \geq \bar{q}_{2}^{D^{*}}$ and $\bar{q}_{1}^{I D^{*}} \geq \bar{q}_{2}^{I D^{*}}$, where $\bar{q}_{1}^{I D^{*}}=\left(D-k\left(c+v_{s}\right)\right) / 2, \bar{q}_{2}^{I D^{*}}=(D-k(c+$ $\left.\left.p_{s}\right)\right) / 2, \bar{q}_{1}^{D^{*}}=\left(D-k\left(c+v_{s}\right)\right) / 4$, and $\bar{q}_{2}^{D^{*}}=\left(D-k\left(c+p_{s}\right)\right) / 4$. It is not hard to verify $\bar{q}_{1}^{I D^{*}} \geq \bar{q}_{1}^{D^{*}}$ and $\bar{q}_{2}^{I D^{*}} \geq \bar{q}_{2}^{D^{*}}$. As the relation between $\bar{q}_{1}^{D^{*}}$ and $\bar{q}_{2}^{I D^{*}}$ is not known, the following two cases are discussed.

(i) When $\bar{q}_{2}^{I D^{*}} \leq \bar{q}_{1}^{D^{*}}, \bar{q}_{2}^{D^{*}} \leq \bar{q}_{2}^{I D^{*}} \leq \bar{q}_{1}^{D^{*}} \leq \bar{q}_{1}^{I D^{*}}$ is got.

In this case, when $0 \leq Q \leq \bar{q}_{2}^{D^{*}}, q^{I D^{*}}=\bar{q}_{2}^{I D^{*}}, q_{r}^{D^{*}}=\bar{q}_{2}^{D^{*}}$; when $\bar{q}_{2}^{D^{*}} \leq Q \leq \bar{q}_{2}^{I D^{*}}, q^{I D^{*}}=\bar{q}_{2}^{I D^{*}}, q_{r}^{D^{*}}=Q$; when $\bar{q}_{2}^{I D^{*}} \leq$ $Q \leq \bar{q}_{1}^{D^{*}}, q^{I D^{*}}=Q, q_{r}^{D^{*}}=Q$; when $\bar{q}_{1}^{D^{*}} \leq Q \leq \bar{q}_{1}^{I D^{*}}, q^{I D^{*}}=Q$, $q_{r}^{D^{*}}=\bar{q}_{1}^{D^{*}}$; when $\bar{q}_{1}^{I D^{*}} \leq Q \leq \bar{Q}, q^{I D^{*}}=\bar{q}_{1}^{I D^{*}}, q_{r}^{D^{*}}=\bar{q}_{1}^{D^{*}}$. It is not hard to get $q_{r}^{D^{*}} \leq q^{I D^{*}}$, when $\bar{q}_{2}^{I D^{*}} \leq \bar{q}_{1}^{D^{*}}$.

(ii) When $\bar{q}_{2}^{I D^{*}} \geq \bar{q}_{1}^{D^{*}}, \bar{q}_{2}^{D^{*}} \leq \bar{q}_{1}^{D^{*}} \leq \bar{q}_{2}^{I D^{*}} \leq \bar{q}_{1}^{I D^{*}}$ is got.

In this case, when $0 \leq Q \leq \bar{q}_{2}^{D^{*}}, q^{I D^{*}}=\bar{q}_{2}^{I D^{*}}, q_{r}^{D^{*}}=\bar{q}_{2}^{D^{*}}$; when $\bar{q}_{2}^{D^{*}} \leq Q \leq \bar{q}_{1}^{D^{*}}, q^{I D^{*}}=\bar{q}_{2}^{I D^{*}}, q_{r}^{D^{*}}=Q$; when $\bar{q}_{1}^{D^{*}} \leq$ $Q \leq \bar{q}_{2}^{I D^{*}}, q^{I D^{*}}=\bar{q}_{2}^{I D^{*}}, q_{r}^{D^{*}}=\bar{q}_{1}^{D^{*}}$; when $\bar{q}_{2}^{I D^{*}} \leq Q \leq \bar{q}_{1}^{I D^{*}}$, $q^{I D^{*}}=Q, q_{r}^{D^{*}}=\bar{q}_{1}^{D^{*}}$; when $\bar{q}_{1}^{I D^{*}} \leq \mathrm{Q} \leq \overline{\mathrm{Q}}, q^{I D^{*}}=\bar{q}_{1}^{I D^{*}}$, $q_{r}^{D^{*}}=\bar{q}_{1}^{D^{*}}$.

It is not hard to get $q_{r}^{D^{*}} \leq q^{I D^{*}}$, when $\bar{q}_{2}^{I D^{*}} \geq \bar{q}_{1}^{D^{*}}$.

Proof of Theorem 6. Because the relation between $(D-k(c+$ $\left.\left.p_{s}\right)\right) / 2,\left(D-k\left(c+v_{s}\right)\right) / 4$ is not known, the following two cases are discussed.

Case 1. When $\left(D-k\left(c+p_{s}\right)\right) / 2 \leq\left(D-k\left(c+v_{s}\right)\right) / 4$, The following five cases are discussed.

(i) When $Q \leq Q \leq\left(D-k\left(c+p_{s}\right) / 4\right), \pi^{I D^{*}}=(1 / k)[(D-$ $\left.\left.k\left(c+p_{s}\right)\right) / 2\right]^{2}+p_{s} Q, \pi^{D^{*}}=(3 / k)\left[\left(D-k\left(p_{s}+c\right)\right) / 4\right]^{2}+$ $p_{s} Q$. It is obvious that $\pi^{I D^{*}} \geq \pi^{D^{*}}$.

(ii) When $\left(D-k\left(c+p_{s}\right)\right) / 4 \leq Q \leq\left(D-k\left(c+p_{s}\right)\right) / 2, \pi^{I D^{*}}=$ $(1 / k)\left[\left(D-k\left(c+p_{s}\right)\right) / 2\right]^{2}+p_{s} Q, \pi^{D^{*}}=Q(((D-Q) /$ $k)-c)$. Because $\pi^{D^{*}}$ is an increasing function of $Q$ and $\pi^{D^{*}}\left(\left(D-k\left(c+p_{s}\right) / 2\right)\right)=\pi^{I D^{*}}$, it's obvious that $\pi^{I D^{*}} \geq \pi^{D^{*}}$. 
(iii) When $\left(D-k\left(c+p_{s}\right)\right) / 2 \leq Q \leq\left(D-k\left(c+v_{s}\right)\right) / 4$, $\pi^{I D^{*}}=Q(((D-Q) / k)-c), \pi^{D^{*}}=Q(((D-Q) / k)-c)$. It is obvious that $\pi^{I D^{*}}=\pi^{D^{*}}$.

(iv) When $\left(D-k\left(c+v_{s}\right)\right) / 4 \leq Q \leq\left(D-k\left(c+v_{s}\right)\right) / 2, \pi^{I D^{*}}=$ $Q((((D-Q)) / k)-c), \pi^{D^{*}}=(3 / k)\left[\left(D-k\left(v_{s}+c\right)\right) / 4\right]^{2}+$ $v_{s} Q$. Because $\pi^{I D^{*}}$ is an increasing function of $Q$ and $\pi^{I D^{*}}\left(\left(D-k\left(c+v_{s}\right)\right) / 4\right)=\pi^{I D^{*}}$, it is obvious that $\pi^{I D^{*}} \geq$ $\pi^{D^{*}}$.

(v) When $\left(D-k\left(c+v_{s}\right)\right) / 2 \leq Q \leq \bar{Q}, \pi^{I D^{*}}=(1 / k)[(D-$ $\left.\left.k\left(c+v_{s}\right)\right) / 2\right]^{2}+v_{s} Q, \pi^{D^{*}}=(3 / k)\left[\left(D-k\left(v_{s}+c\right)\right) / 4\right]^{2}+$ $v_{s}$ Q. It is obvious that $\pi^{I D^{*}} \geq \pi^{D^{*}}$.

Case 2. When $\left(D-k\left(c+v_{s}\right)\right) / 4 \leq\left(D-k\left(c+p_{s}\right)\right) / 2$, The following five cases are discussed.

(i) When $Q \leq Q \leq\left(D-k\left(c+p_{s}\right)\right) / 4, \pi^{I D^{*}}=(1 / k)[(D-$ $\left.\left.k\left(c+p_{s}\right)\right) / 2\right]^{2}+p_{s} Q, \pi^{D^{*}}=(3 / k)\left[\left(D-k\left(p_{s}+c\right)\right) / 4\right]^{2}+$ $p_{s} Q$. It is obvious that $\pi^{I D^{*}} \geq \pi^{D^{*}}$.

(ii) When $\left(D-k\left(c+p_{s}\right)\right) / 4 \leq Q \leq\left(D-k\left(c+v_{s}\right)\right) / 4, \pi^{I D^{*}}=$ $(1 / k)\left[\left(D-k\left(c+p_{s}\right)\right) / 2\right]^{2}+p_{s} Q, \pi^{D^{*}}=Q(((D-Q) /$ $k)-c)$. Because $\pi^{D^{*}}$ is an increasing function of $Q$ and $\pi^{D^{*}}\left(\left(D-k\left(c+v_{s}\right)\right) / 4\right)<\pi^{I D^{*}}$, it's obvious that $\pi^{I D^{*}} \geq \pi^{D^{*}}$.

(iii) When $\left(D-k\left(c+v_{s}\right)\right) / 4 \leq Q \leq\left(D-k\left(c+p_{s}\right)\right) / 2$, $\pi^{I D^{*}}=(1 / k)\left[\left(D-k\left(c+p_{s}\right)\right) / 2\right]^{2}+p_{s} Q, \pi^{D^{*}}=$ $(3 / k)\left[\left(D-k\left(v_{s}+c\right)\right) / 4\right]^{2}+v_{s} Q$. It is obvious that $\pi^{I D^{*}} \geq \pi^{D^{*}}$.

(iv) When $\left(D-k\left(c+p_{s}\right)\right) / 2 \leq Q \leq\left(D-k\left(c+v_{s}\right)\right) / 2, \pi^{I D^{*}}=$ $Q(((D-Q) / k)-c), \pi^{D^{*}}=(3 / k)\left[\left(D-k\left(v_{s}+c\right)\right) / 4\right]^{2}+$ $v_{s} Q$. Because $\pi^{I D^{*}}$ is an increasing function of $Q$ and $\pi^{I D^{*}}\left(\left(D-k\left(c+p_{s}\right)\right) / 2\right)>\pi^{D^{*}}$, it is obvious that $\pi^{I D^{*}} \geq$ $\pi^{D^{*}}$.

(v) When $\left(D-k\left(c+v_{s}\right)\right) / 2 \leq Q \leq \bar{Q}, \pi^{I D^{*}}=(1 / k)[(D-$ $\left.\left.k\left(c+v_{s}\right)\right) / 2\right]^{2}+v_{s} Q, \pi^{D^{*}}=(3 / k)\left[\left(D-k\left(v_{s}+c\right)\right) / 4\right]^{2}+$ $v_{s}$ Q. It is obvious that $\pi^{I D^{*}} \geq \pi^{D^{*}}$.

In summary, $\pi^{I D^{*}} \geq \pi^{D^{*}}$ is always true.

Proof of Theorem 7. From the retailer's profit in the decentralized supply chain given in (2), the best response $q_{r}^{C^{*}}(\omega)=$ $(D-k \omega) / 2$ is got. To ensure that the retailer's order quantity equals the optimal order quantity in the centralized supply chain, that is, $q_{r}^{C^{*}}(\omega)=q^{I D^{*}}$, the results in Theorem 8 are obtained.

Proof of Theorem 8. (i) When $0 \leq Q \leq\left(D-k\left(c+p_{s}\right)\right) / 2$, the supplier and retailer's profits are $\pi_{s}^{C^{*}}=p_{s} Q, \pi_{r}^{C^{*}}=$ $(1 / k)\left[\left(D-k\left(p_{s}+c\right)\right) / 2\right]^{2}$. The total supply chain profit is: $\pi^{C^{*}}=(1 / k)\left[\left(D-k\left(c+p_{s}\right)\right) / 2\right]^{2}+p_{s} Q$

(ii) when $\left(D-k\left(c+p_{s}\right)\right) / 2 \leq Q \leq\left(D-k\left(c+v_{s}\right)\right) / 2$, The supplier and retailer's profits are $\pi_{s}^{C^{*}}=Q(((D-2 Q) / k)-c)$,
$\pi_{r}^{C^{*}}=Q^{2} / k$. The total supply chain profit is $\pi^{C^{*}}=Q(((D-Q) /$ k) $-c)$;

(iii) when $\left(D-k\left(c+v_{s}\right)\right) / 2 \leq Q \leq \bar{Q}$, the supplier and retailer's profits are $\pi_{s}^{C^{*}}=v_{s} Q, \pi_{r}^{C^{*}}=$ $(1 / k)\left[\left(D-k\left(v_{s}+c\right)\right) / 2\right]^{2}$. The total supply chain profit is $\pi^{C^{*}}=(1 / k)\left[\left(D-k\left(c+v_{s}\right)\right) / 2\right]^{2}+v_{s} Q$.

Summarizing the above results, $\pi^{C^{*}}=\pi^{I D^{*}}$ is got; that is, the decentralized supply chain is coordinated.

\section{Acknowledgments}

This work was supported by the National Natural Science Foundation of China (Grant no. 71002077), National Social Science Foundation of China (Grant no. 10BJY073), Soft Scientific Research Project of Shandong Province (Grant no. 2011RKGB3012), Humanity and Social Science Youth foundation of Ministry of Education (Grant no. 10YJC630017), Promotive Research Fund for Excellent Young and Middle-aged Scientists of Shandong Province (Grant no. BS2011DX026), twelfth five-year-plan national science and technology project for the rural development in China (2011BAD24B03).

\section{References}

[1] B. Samuel, C. J. Philip, and J. L. Timothy, "Coordinating the supply chain in the agricultural seed industry," European Journal of Operational Research, vol. 185, no. 1, pp. 354-377, 2008.

[2] Y. B. Xiao, J. Chen, and X. L. Xu, "Fresh product supply chain coordination under CIF business model with long distance transportation," Systems Engineering, vol. 28, no. 2, pp. 19-34, 2008.

[3] J. Wang and X. Chen, "Fresh produce supplier's pricing decisions research with circulation wastage and options contracts," Forecasting, vol. 30, no. 5, pp. 42-47, 2011.

[4] X. Q. Cai, J. Chen, Y. B. Xiao et al., "Fresh-product supply chain management with logistics outsourcing," Omega, vol. 41, no. 4, pp. 752-765, 2013.

[5] M. Yu and A. Nagurney, "Competitive food supply chain networks with application to fresh produce," European Journal of Operational Research, vol. 224, no. 1, pp. 273-282, 2013.

[6] M. A. Lariviere, "Supply chain contracting and coordination with stochastic demand," in Quantitative Models for Supply Chain Management, S. Tayur, R. Ganeshan, and M. Magazine, Eds., pp. 233-268, Kluwer Academic, Boston, Mass, USA, 1999.

[7] A. Tsay, S. Nahmias, and N. Agrawal, "Modeling supply chain contracts: a review," in Quantitative Models for Supply Chain Management, S. Tayur, M. Magazine, and R. Ganeshan, Eds., pp. 197-232, Kluwer Academic, Boston, Mass, USA, 1998.

[8] G. P. Cachon, "Supply chain coordination with contracts", in Handbook in Operation Research and Management Science: Supply Chain Management, S. Graves and A. G. de Kok, Eds., North-Holland, Berlin, Germany, 2003.

[9] A. P. Jeuland and S. M. Shugan, "Managing channel profits," Marketing Science, vol. 2, no. 3, pp. 239-272, 1983.

[10] K. S. Moorthy, "Managing channel profits: comments," Marketing Science, vol. 6, no. 4, pp. 375-379, 1987.

[11] Z. Georges, "On the coordination of dynamic marketing channels and two-part tariffs," Automatica, vol. 44, no. 5, pp. 1233$1239,2008$. 
[12] X. T. Qi, J. F. Bard, and G. Yu, "Supply chain coordination with demand disruptions," Omega, no. 32, pp. 301-312, 2004.

[13] T. J. Xiao, G. Yu, Z. H. Sheng, and Y. S. Xia, "Coordination of a supply chain with one-manufacturer and two-retailers under demand promotion and disruption management decisions," Annals of Operations Research, vol. 135, no. 1, pp. 87-109, 2005.

[14] T. J. Xiao and G. Yu, "Supply chain disruption management and evolutionarily stable strategies of retailers in the quantitysetting duopoly situation with homogeneous goods," European Journal of Operational Research, vol. 173, no. 2, pp. 648-668, 2006.

[15] T. J. Xiao and X. T. Qi, "Price competition, cost and demand disruptions and coordination of a supply chain with one manufacturer and two competing retailers," Omega, vol. 36, no. 5, pp. 741-753, 2008.

[16] K. Chen and T. J. Xiao, "Demand disruption and coordination of the supply chain with a dominant retailer," European Journal of Operational Research, vol. 197, no. 1, pp. 225-234, 2009.

[17] J. Li, S. Y. Wang, and T. C. E. Cheng, "Competition and cooperation in a single-retailer two-supplier supply chain with supply disruption," International Journal of Production Economics, vol. 124, no. 1, pp. 137-150, 2010.

[18] S. Huang, C. Yang, and X. Zhang, "Pricing and production decisions in dual-channel supply chains with demand disruptions," Computers \& Industrial Engineering, vol. 62, no. 1, pp. 70-83, 2012.

[19] X. Anastasios, V. Dimitrios, and I. Eleftherios, "Optimal newsvendor policies for dual-sourcing supply chains: a disruption risk management framework," Computers \& Operations Research, no. 39, pp. 350-357, 2012. 


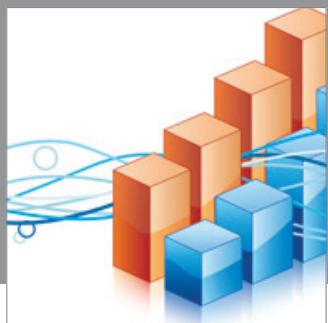

Advances in

Operations Research

mansans

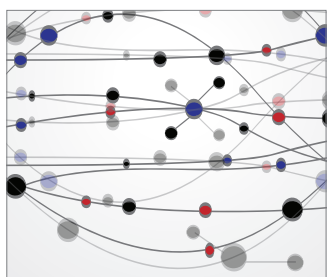

The Scientific World Journal
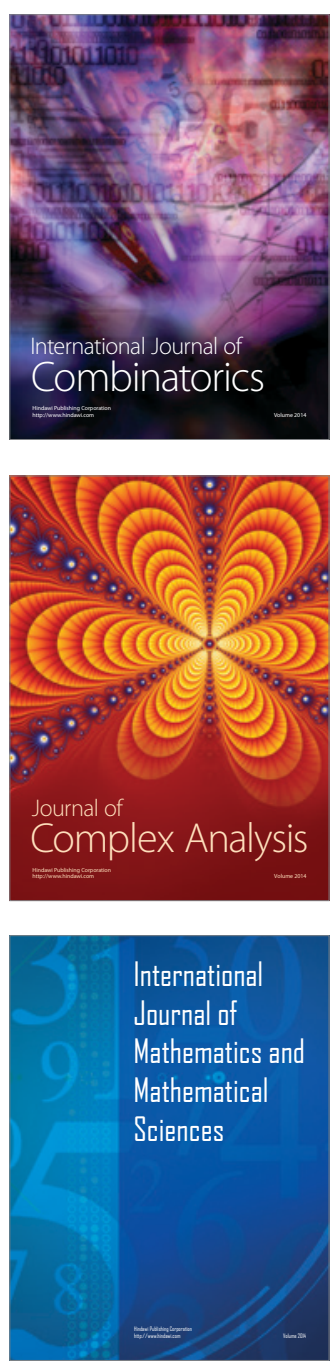
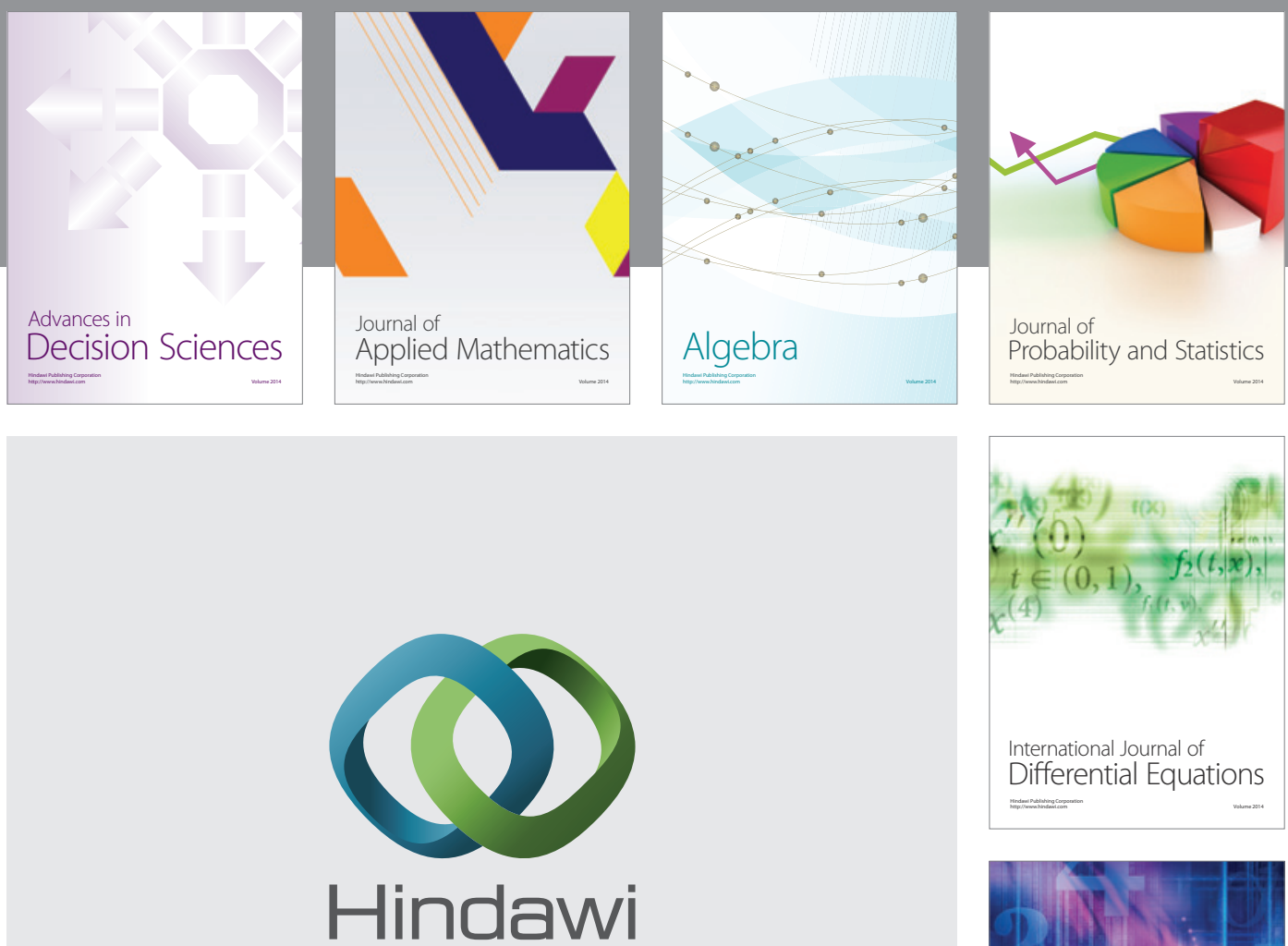

Submit your manuscripts at http://www.hindawi.com
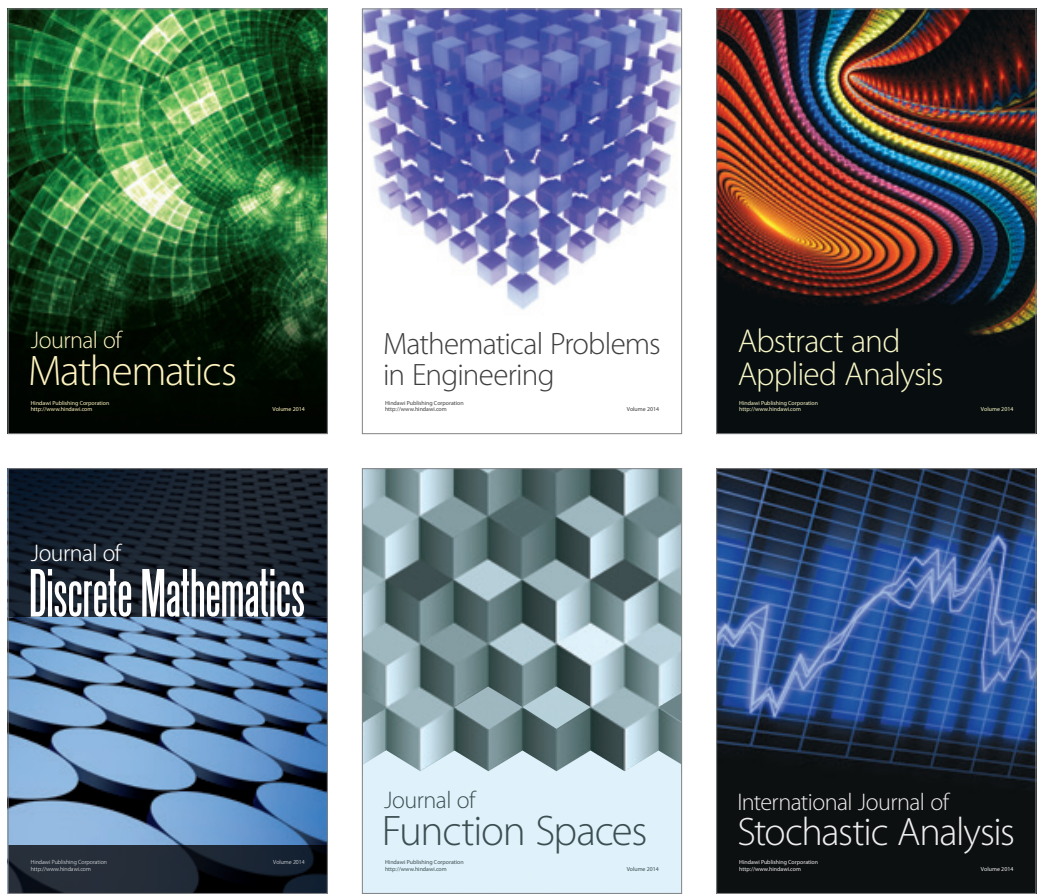

Journal of

Function Spaces

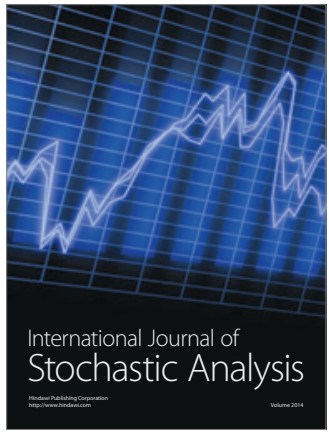

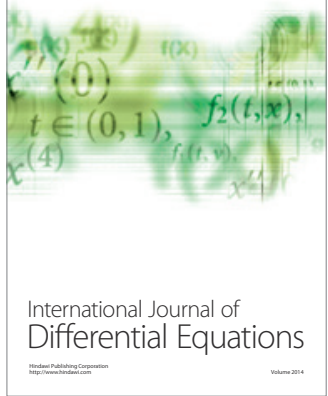
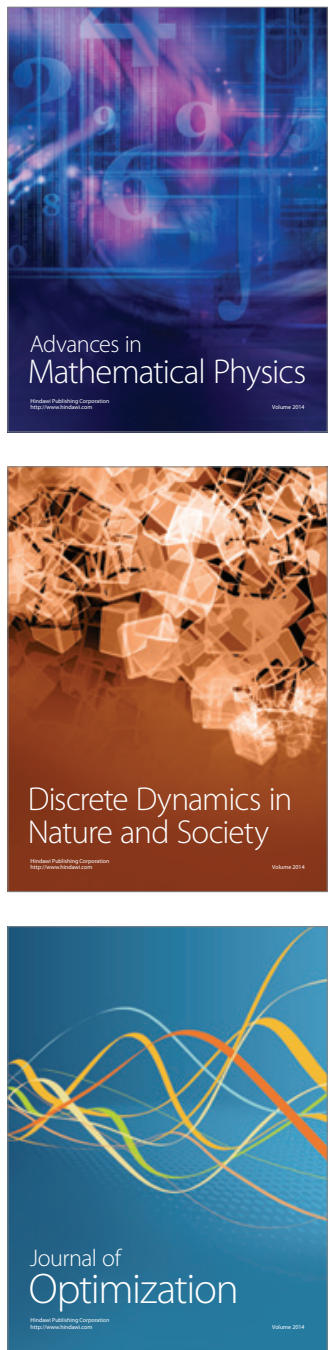